\title{
DSK zu Datenübermittlungen aus Deutschland in das Vereinigte Königreich Großbritannien und Nordirland nach dem „Brexit“
}

Die Konferenz der unabhängigen Datenschutzaufsichtsbehörden des Bundes und der Länder (DSK) weist Unternehmen, Behörden und andere Institutionen in Deutschland mit den folgenden Informationen auf die Rechtslage bei einem Austritt („Brexit $^{\text {") }}$ des Vereinigten Königreichs Großbritannien und Nordirland (im Folgenden: VK) aus der Europäischen Union (EU) hin. Möglich sind zwei Szenarien:

\section{Geregelter Austritt}

Für den Fall eines geregelten Austritts („Deal-Brexit“) gilt nach den Vorgaben des vorliegenden Entwurfs eines Austrittsabkommens ${ }^{1}$ zwischen der EU und dem VK die Datenschutz-Grundverordnung (DSGVO) weiter. Das Abkommen sieht nämlich einen Übergangszeitraum vom 30. März 2019 bis Ende 2020 vor (Art. 126). Während dieser Zeit ist das EU-Recht, also auch die DSGVO mit ihren Vorgaben für Datenverarbeitungen, nach wie vor auch im VK anzuwenden (Art. 127), so als wäre das Land weiterhin ein EU-Mitgliedstaat und kein Drittland im Sinne der DSGVO.

Eine Verlängerung des Übergangszeitraums um ein bzw. zwei Jahre ist einmalig und vor dem 1. Juli 2020 möglich (Art. 132).

Während des Übergangszeitraums dürfen personenbezogene Daten in das VK unter denselben Voraussetzungen wie bisher übermittelt werden.

\section{Ungeregelter Austritt}

Für den Fall eines ungeregelten Austritts („No-Deal-Brexit“) wird das VK zu einem Drittland im Sinne der DSGVO. Verantwortliche, die personenbezogene Daten an Partner im VK übermitteln wollen, müssen ab dem 30. März 2019 ihre Datenübermittlungen mit den besonderen Maßnahmen nach Kapitel V DSGVO absichern. Die DSK verweist nachdrücklich auf die vom Europäischen Datenschutzausschuss (EDSA) veröffentlichte Informa-

1 ABI. EU vom 19. Februar 2019, C 66I, S. 1 ff. (198 Seiten), abrufbar unter https://eur-lex.europa.eu/legal-content/EN/TXT/?uri=0J\%3AC\%3A2019\%3A066I $\% 3$ ATOC tion $^{2}$, die von allen datenübermittelnden Stellen unbedingt zu beachten ist.

Eine inoffizielle deutsche Arbeitsübersetzung ${ }^{3}$ ist ebenfalls verfügbar. Im Wesentlichen ist demnach Folgendes zu tun: Bei einer Datenübermittlung in das Drittland VK sollten die Verantwortlichen

1. feststellen, welche Verarbeitungen eine Übermittlung personenbezogener Daten in das Drittland VK mit sich bringen,

2. das geeignete Datentransfer-Instrument für die jeweilige Situation festlegen,

3. das gewählte Datentransfer-Instrument so umsetzen, dass es für den für den Austrittstermin bereit ist,

4. in der internen Dokumentation vermerken, dass Übermittlungen in das Drittland VK erfolgen werden und

5. die Datenschutzerklärung zur Information der betroffenen Personen entsprechend aktualisieren.

Konkretisierend zu den unter Schritt 4 und 5 genannten sind insbesondere folgende Maßnahmen vorzusehen: a) Im Informationsblatt zur Datenverarbeitung und in der Datenschutzerklärung einer Webseite ist über die Datenübermittlung in das Drittland VK und über die verwendeten geeigneten Datenschutzgarantien zu informieren (Art. 13 Abs. 1 lit. fbzw. Art. 14 Abs. 1 lit. fDSGVO). b) Wenn eine betroffene Person von ihrem Auskunftsrecht Gebrauch macht, ist sie auch über die Datenübermittlung in das Drittland VK und die verwendeten geeigneten Datenschutzgarantien zu informieren (Art. 15 Abs. 1 lit. c, Abs. 2 DSGVO). c) Im Verzeichnis von Verarbeitungstätigkeiten sind Datenübermittlungen in das Drittland VK als solche zu bezeichnen und die weiteren in diesem Zusammenhang geforderten Angaben zu machen (Art. 30 Abs. 1 lit. d und lit. e DSGVO bzw. Art. 30 Abs. 2 lit. c DSGVO). Die DSK weist darauf hin, dass Verantwortliche, die personenbezogene Daten ohne die nach Kapitel V DSGVO notwendigen Sicherheiten in das VK übermitteln, rechtswidrig handeln. Die Aufsichtsbehörden könnten dann Datenübermittlungen per Anordnung aussetzen (Art. 58 Abs. 2 lit. j DSGVO) und Geldbußen verhängen (Art. 83 Abs. 5 lit. c DSGVO).

2 https://www.bfdi.bund.de/SharedDocs/Publikationen/Dokumente-Art29Gruppe_EDSA/SonstigePapiere/EDSA_Info_NoDealBrexit.html?nn=5217120

3 https://www.bfdi.bund.de/SharedDocs/Publikationen/DokumenteArt29Gruppe_EDSA/SonstigePapiere/EDSA_Info_NoDealBrexit_Arbeits $\%$ C $3 \% B C$ bersetzung.html?nn $=5217120$ 